\title{
WhatsApp Activities for Enhancing TEFL Pedagogical Knowledge and Classroom Practices: Suggested Types and Student-Teachers' Reflection
}

\author{
Sumer Salman Abou Shaaban ${ }^{1}$ \\ ${ }^{1}$ E-Learning and TEFL, Al-Azhar University - Gaza, Palestine \\ Correspondence: Sumer Salman Abou Shaaban, Al-Azhar University - Gaza, Jamal Abed Al-Nazer Street, Gaza, \\ Palestine.
}

Received: November 11, 2020

doi: $10.5539 /$ elt.v13n12p102

\begin{abstract}
This research was conducted to suggest a set of WhatsApp activities to enhance pedagogical knowledge and classroom practices that can be used in TEFL courses and to explore student-teachers' reflection towards the use of WhatsApp and the suggested activities. By reviewing related literature of using social networks and WhatsApp and though interviewing (9) TEFL instructors and (17) TEFL student-teachers, the researcher was able to suggest several activities that were used effectively in TEFL courses. These activities are: (1) reading materials (2) prediction ideas to get interest for the next lecture (3) videos (4) questions for flip classes or reviewing questions or proposing a problem to solve (5) open discussion topics or reflection on the lecture. A set of bases for using WhatsApp activities such as: posting clear content and having clear instructions for doing the activity, meeting FL student-teachers' language level or little higher language level, and not overloading TEFL student-teachers was presented. A group of (104) TEFL student-teachers from the faculty of education at Al-Azhar University-Gaza completed the following three reflection questions: what are the benefits of using WhatsApp and the suggested activities? What are the disadvantages of using WhatsApp and the suggested activities? What are the recommendations for improving the usage of WhatsApp applications and the suggested activities? Their responses were analysed qualitatively and quantitatively. The most common benefits were classified under (a.) pedagogical knowledge (b.) classroom practices (c.) review and evaluation (quizzes or tests) (d.) course requirements. On the other hand, the mentioned disadvantages were classified as (a.) technical and security problems (b.) communication problems.
\end{abstract}

Keywords: WhatsApp activities, TEFL course, pedagogical knowledge, classroom practices, student-teachers, reflection

\section{Introduction}

\subsection{Introduce the Problem}

In the pace of the twenty first century due to the information and communications technology, all life traits were affected. Technology with its devices, appliances and applications has invaded every aspect of our life to the extent that people nowadays cannot do without it. Hence, its role and uses are inevitable. One of the widely affected sectors is education. The aspiration of the excessive use of smart devices in all life matters has affected the teaching methods and students' desire of learning. In view of this fact, these days the Web 2.0 social network has been used by most of students in all education levels, for social relations and even for fun (Hamad, 2017, p.74). The students use current technology in sharing content, having fun, communicating, creating community, and learning (Meşe \& Aydın, 2019, p. 190).

As a result, instructors were invited to understand students' smart devices and social networking usage purposes and the reasons that may affect their way of thinking, understanding, interaction and even learning (Meşe \& Aydin, 2019, p. 190). In fact, not only the twenty-first century students access these devices but also the teachers have access to numerous digital tools for communication and collaboration. This motivates the teachers apply these tools in interactions, in teaching and learning settings "to blurring the boundaries between schools and community and allowing for more informal interactions not only to contribute to classroom knowledge 
production but also in fostering the emotional bonding that is necessary in creating safe, trusting, and effective learning spaces" (Adams, 2019, p. 124).

The adaptation of smart devices applications in classroom is so useful in TEFL. "Facilitate the teaching and learning process even outside the classroom (Robles, Guerrero, Llinás, and Montero, 2019, p. 246). It turns out to be an innovative trend that derives in better outcomes for both parties." One of the most prominent and widely used smart devices applications is WhatsApp. WhatsApp application seems to be simple, easy and interesting to use for many people belonging to different age groups, trades, and interests. It is currently used in over 180 countries, and over 50 million messages are sent via WhatsApp every day. As of July 2017, more than 1.7 billion people were actively using WhatsApp, which makes it the world's second-largest social network" (Alderman, 2017). Besides, it is popular and free to download messenger application for smartphones and desktop. It enables users to share documents directly from Google Drive and iCloud Drive. Moreover, it can be used to send videos, audio messages, and pictures.

In race of WhatsApp innovation facilities in pedagogy, there are a lot of strong affirmations pointed out in the related literature about the adaptions of WhatsApp facilities in the teaching activities. The role of WhatsApp in strengthening the interaction between the students, closing of distance between the teacher and the students, breaking the myth of the inconvenience of electronic devices in the student's learning process and makes it an ally (Robles, Guerrero, Llinás \& Montero, 2019, p. 246) WhatsApp provides students with good study habits at home, useful platform for connecting students during out-of-school time, effective tool for sharing information and engaging in discussion (Adams, 2019, p.116). By the same token, it is a learning platform which enables learning anytime and anywhere, encourages collaboration, extends learning time, manages large class sizes, flips the classroom, builds confidence, contributes to student achievement on exams with both the instant knowledge and using the media as motivating factors, nurtures social relation by creating dialogue and encourages sharing among students (Bloder \& Waldman, 2019, p. 123). In addition, WhatsApp helps shy students to participate effectively, saves time, gives equal opportunities of participation for all students and hence every student gets involved in the learning event, supports formal and informal learning, helps students get support from their peers, and from their instructors, and improves reading and writing skills by participating in reading materials (Alsowaye \& Garba, 2019, p. 93-94).

It is obvious that the WhatsApp is a useful and immensely used technology for different learning and teaching settings. Through this easily applied technology, the different learning and teaching elements are implemented. In the field of TEFL, for instance, students can make use of it to enhance their language skills and language elements alike. As for teachers, they use it to upload the different activities, assignments and support materials for their students. In addition, it helps building up friendly relations among a wide range of students themselves on the one hand and establishing rapport between teachers and their students on the other.

Nonetheless, despite the innovation facilities, there are few challenges that have to be considered during the implantation of WhatsApp and smart devices applications in teaching/learning contexts. "WhatsApp has several challenges that might cause the flooding of irrelevant or nonsensical use in education settings. The group hours might burden and annoy the users, especially if they have more than one group or a group that includes more than 15 members" (Bloder \& Waldman, 2019, p. 123). Other set of challenges are the option to join group, mobile memory overload and the inability to block unrelated posts of the unwelcomed visitors (Alsowayegh Garba, 2019, p. 94). Annamalai (2019) concluded that when using WhatsApp as an extended learning platform, students face technical problems, difficulties to gather all the information posted by the group members and sometimes to identify the sender of the message.

\subsection{Previous Studies}

The use of ICT, social networks and WhatsApp in teaching and learning EFL/ ESL was the aim of several studies, for instance, Abou Shaaban, Abu Shawish and Jalambo (2019) shed the light on the importance of information and communications technology (ICT) integration in EFL/ESL teachers' training. A group of (64) trainers from different countries (Palestine, UK, USA, Iran, Lebanon, Yemen, Iraq) revealed that Emails, mobile applications, and Google are often used, whereas Wikis were never used in training EFL/ ESL teachers. However, Annamalai (2019) explored a small group of undergraduates' in the Malaysian reflection towards the use of WhatsApp as an extended learning platform. They showed that the majority of undergraduates supported the online interaction archives and they mentioned some problems related to WhatsApp use such as: Technical problems, difficult to gather all the information if once the phone is problematic and identifying the sender of the message. 
In addition, Meşe and Aydın (2019) sought to find out the usage purposes of social networking and the variables that determine the purpose of using social network in (549) undergraduate students using social network in terms of learning environments. They indicated that there is a difference in favor of women in initiating communication in favor of men and that those who use social networks for a long time share more content and the social networks of WhatsApp and Instagram are the most widely used.

Besides, Annamalai (2018) investigated how two lecturers and (12) pre-service teachers used WhatsApp in educational context and the teaching approach integrated with it. The lecturers mentioned that they employed blended learning approach and were not keen to entirely conduct their lessons in the online learning environment. Pre-service teachers mentioned the positive themes were related to bite size learning, seamless learning, 21st century learning, WhatsApp as a platform to support learning and as an extended interaction space. Similarly, Bensalem and Al-Zubaidi (2018) revealed that WhatsApp group significantly outperformed the traditional group on a vocabulary knowledge test and they have positive attitudes towards learning new vocabulary items via WhatsApp.

Furthermore, Mbukusa (2018) found out that Namibia University students enjoy using WhatsApp as a tool for learning and so he calls for institutions to offer internet amenities as a top urgency in contemporary instruction. On the other hand, those who do not own smart phones hold negative attitudes towards using WhatsApp. They maintained that WhatsApp platform shows a variance on balancing online activities and academic preparation, and distracts students from completing their assignments and adhering to their private studies timetable.

Moreover, Hamad (2017) explored that almost all students supported using WhatsApp to enhance students learning and enthusiasm. They maintained that using WhatsApp helped students to develop English skills, enriched their vocabulary and learn from their mates' mistakes, although the study laid out some disadvantages of the experience such as preparing the materials and having discipline in the group. By the same token, Badawi (2009) investigated the effectiveness of using blended learning model in developing EFL prospective teachers' pedagogical knowledge and performance. The results of the pedagogical knowledge test revealed that the mean scores of the EFL prospective teachers in the blended group surpassed the mean scores of those who were in the traditional face-to-face group, whereas there were no significant differences between the two groups in terms of their mean scores on the pedagogical performance scale.

The aforementioned studies showed a vital role and purposes of ICT and WhatsApp application implantations in the FL learning/ teaching context and the satisfaction towards the usage such as Abou Shaaban, Abu Shawish and Jalambo (2019) and Bansalem and Al-Zubaidi (2018). Some studies showed the way of using such applications in educational context such as Annamalai (2018). To complete and confirm what has been revealed in the previous studies results, this research came up as an attempt to suggest some WhatsApp activities which may help in achieving the purposes of TEFL courses. Besides, this study seeks to point out bases for successful use of WhatsApp in TEFL courses and improve this use by revealing TEFL student-teachers' reflection towards the usage and the suggested activities.

\subsection{Statement of the Problem}

In order to grip TEFL student-teachers' interest and to enhance positive energy towards TEFL courses, it is crucial to find and consolidate teaching techniques and activities that integrate theoretical pedagogical knowledge and practical aspects. This cannot be achieved without implementing a mediator through which a continuous link between TEFL resources and TEFL student-teachers can be formed. The importance of this study stems from the inclusion of a set of WhatsApp activities, the bases of using WhatsApp activities with TEFL student-teachers and the reflection presented by TEFL student-teachers. This may help in improving the use of WhatsApp for educational purposes and the objectives as determined not only for TEFL courses but also for different educational courses.

\subsection{Objectives of the Study}

- This study seeks to shed light to some WhatsApp activities that can be used to enhance TEFL student-teachers' pedagogical knowledge and classroom practices.

- It presents the bases of using WhatsApp activities to be considered by both the instructor and the TEFL student-teacher as well in order to guarantee a successful use of WhatsApp.

- It also highlights TEFL student-teachers' reflection towards the use of WhatsApp activities in TEFL courses. 


\section{Method}

The Method section describes in detail how the study was conducted, including conceptual and operational definitions of the variables used in the study, Different types of studies will rely on different methodologies; however, a complete description of the methods used enables the reader to evaluate the appropriateness of your methods and the reliability and the validity of your results, It also permits experienced investigators to replicate the study, If your manuscript is an update of an ongoing or earlier study and the method has been published in detail elsewhere, you may refer the reader to that source and simply give a brief synopsis of the method in this section.

\subsection{Delimitations of the Study}

The present study was conducted during the second semester of the academic year 2018/2019 on (104) third level female TEFL student-teachers from the faculty of education, AL-Azhar University-Gaza AUG. It focuses on enhancing theoretical and practical TEFL aspects.

\subsection{Research Design}

The current quantitative and qualitative research adopted the descriptive analytical research approach. The researcher reviewed the literature related to the use of WhatsApp in teaching and learning to find out suitable activities and bases for using these activities in a suitable and stimulating teaching environment. Besides, the researcher conducted a focus group with (9) TEFL instructors and (17) TEFL student-teachers to review the suggested WhatsApp activities. A group of (104) TEFL student-teachers from the faculty of education at AUG participated in the WhatsApp TEFL course group in the second semester of the academic year (2018/2019). By the end of the semester, the TEFL student-teachers' reflected on the use of WhatsApp and the suggested activities by talking about three points: the benefits of using WhatsApp activities, the disadvantages and recommendations for improving the use of WhatsApp in TEFL courses.

\section{Results and Discussion}

3.1 The Suggested Types of WhatsApp Activities to Enhance TEFL Student-Teachers' Pedagogical Knowledge and Classroom Practices

Reviewing literature related to using WhatsApp in teaching and learning, conducting a focus group with a number of TEFL instructors from different universities and asking TEFL student-teachers helped the researcher to identify the most significant types of WhatsApp activities which can be used in TEFL courses. The activity types are labeled under the following five categories: (1) reading materials such as (a.) scenarios of real classroom situations (b.) articles and books/chapters (c.) practical studies/action researches and (d.) websites (2) prediction ideas to get interest for the next lecture such as (a.) pictures (b.) proverbs and wisdom (c.) puzzles and games (3) videos about (a.) classroom teaching complete/part lessons (b.) reflection from classroom teachers (c.) explanation for related course chapters (4) questions for flip classes or review questions or problem to solve (5) open discussion topics or reflection on the lecture. The balance in positing these activities according to TEFL courses requirements and the number of these activities in each week during the semester to avoid bothering TEFL student-teachers with these activities is of paramount importance. Below are explanation and procedures of each activity:

\subsubsection{Reading Materials}

Different types of reading materials are posted for TEFL student-teachers such as: scenarios about different classroom situations, a chapter or research paper or article or action research or asking them to find related reading materials to read or post them. The following is an explanation of these materials.

a-Scenarios of real classroom situations motivate learners to participate in an interactive teaching classroom environment. This method is a teaching way using virtual, interactive, problem-based contexts. This strategy involved learners working their way through a problem and they tend to find it a solution (Scenario-based Learning, 2019). Such a learning situation helps TEFL student-teachers promote critical thinking and problem-based or case-based learning and presents real-world contexts that facilitate good learning for classroom practices (Abou Shaaban \& Shaat, 2019, p. 12). Moreover, it "fills the gap between theory and practice in the learning and teaching environment" (TANERI, 2018, p. 57). The researcher considered these points in her study.

\section{Procedures for implementing Scenarios of real classroom situations followed by the researcher:}

- Writing short, realistic scenarios having sequence of teaching events for selected chapters in TEFL courses. 
- Providing each scenario with such questions: what was the learning objective of the situation? Did the teacher achieve it? How do you know? What do you like in this scenario? Why? What did not you like in this scenario? Why? If you were the teacher, what changes are you going to do to help students achieve the learning objective? And the instructor can ask about the stages of the lesson and what did the teacher/ students do in each stage? And why?

- Asking TEFL student-teachers to work in group in analyzing the scenario and in answering their questions.

- Following up answers next lecture directly.

b-Articles, books/ chapters, practical studies/action researches and websites

Posting additional reading materials beside the main reference of the course is referred to as extended reading or further reading material. A group of advice for extended reading materials such as: maximizing learner involvement, student presentation, written work based on the reading, avoiding using text, discouraging the overuse of dictionaries, monitoring the students' reading, and maintaining the entertainment was presented (Bell, 1998). In TEFL courses, extended reading is very important in expanding student-teachers' knowledge in TEFL methods and techniques. Besides, it is a kind of training them for conducting related resources for continual professional development and necessity of being familiar with recent TEFL trends. There are different TEFL materials that can be used for expanding theoretical knowledge and practical skills such as: reading a book or a chapter from a book, reading research papers and reading practical studies or action researches. The instructor can ask TEFL student-teachers to post useful and interesting reading material or website and say why they liked it. Action research is another reading material that presents a complete experience for a school teacher in searching for improving classroom practices in a specific situation or task in systematic logical steps. As a last suggested type of reading material is TEFL websites. These links are very important in cultivated TEFL student-teachers' knowledge with relevant experts, writers, books, researches, real experiences, and related sub-links.

\section{Procedures for implementing articles, books/chapters, practical studies/action researches:}

- Selecting enjoyable short materials, then adding new information for students and giving them choices to select test general comprehension of the text by following the reading material by specific task and encouraging students to read fast as possible as they can (Cox, n. d).

- Asking them to do one of these tasks after or during reading: to summarize the whole idea, to draw a mind map or any other graphic organizer, to complete KWL (know, want to know, learn) table, to prepare themselves for hot seating, to mention interesting points and say why, to answer during reading questions about finding specific details, or to prepare five minutes presentation or to complete the material by suggested related subtopics.

- Following up the reading task/s next lecture directly by using one of these strategies: jigsaw strategy and hot seating, or collecting their achievements and checking them later to give them written feedback.

\subsubsection{Prediction Ideas to Get Interest for the Next Lecture}

Positing picture/s wisdom or proverbs or famous phrases or puzzle game is a strategy that can be used to "gain students' interest to the next lecture topic. This gives them a reason to attend the lecture for and to rose a series of questions to looking for answering them during the lecture or to prepare material or questions for sharing during the lecture" (British Council, n. d.). Here, TEFL student-teachers should predict the topic of the next lecture and figure-out the evidence in the text that stands as an evidence for their predictions. In this way, the instructor asks them to "think about what they already know about the story, and what they think will logically happen next" (BookPagez.com, 2019).

Procedures for implementing prediction ideas such as picture/s wisdom or proverbs or famous phrases or puzzle game:

- Posting picture/s wisdom, proverbs, famous phrases or puzzle game related to the next lecture topic.

- Asking TEFL student teachers to predict the topic of the next lecture. As one idea can be used, the instructor can post three choices as a guided prediction and asks them to choose one.

- As a beginning of the next lecture, asking TEFL student-teacher to vote which choice they selected and what the evidence was in the posted prediction task. 
3.1.3 Videos about Classroom Teaching Complete/Part Lessons, Reflection from Classroom Teachers, Explanation for Related Chapters

Using videos in enhancing teaching practices is so much useful and offers a unique teaching/learning technique as reported by experienced educators. Using videos and watching the complete classroom situation "are incumbent upon teacher education students to develop the capacity to make sense of the events that occur in the classroom" (Rosaen et al., 2008). In addition, it motivates student-teachers to analyze its components, trains them to notice what is occurring in classroom, develops classroom management skills, and enhances reflection skills. Furthermore, it provides student-teachers with the appropriate background to "observe and reflect carefully on different issues of teaching and learning in action. This helps the student-teacher to avoid complacency which can act as a barrier to their growth as educators. Teacher educators can prompt the students to watch for specific elements when viewing their videos which compels the students to look more deeply than they might otherwise have done. Students can be guided to attend to the more sophisticated and less obvious aspects of their teaching in order to gain an in-depth understanding of the multifaceted nature of the classroom. Deeper appreciation of their own teaching behaviors and May, in turn, be more receptive to feedback" (Coffey, 2014, p. 8-9).

Procedures for implementing videos about classroom teaching complete/ part lessons, reflection from classroom teachers, explain for related chapters:

- Selecting appropriate classroom teaching lesson and it could be part or complete lesson. The important issue here is the video should focus on one of the following: presenting the stages of teaching main or sub-skills of one language, matching to next lecture topic, including clear audio and visual material, presenting a short explanation about the next lecture topic, or a classroom teacher reflects on his/her lesson clearly and logically.

- Presenting a set of questions as a guide for student-teachers during following the events of a video.

- Discussing student-teachers' answers and comments in a suitable way during the next lecture.

\subsubsection{Questions for Flip Classes or Review Questions or Problem to Solve}

Questions based-learning or flip classes strategy aims to increase students' ability to hold the tension of not knowing answers and to develop liberal learning and critical thinking by analytical thinking, multiple framing reflective exploration of meaning, and practical reasoning (Muff, 2013, p. 181). In addition, it is a strategy for inquiry to stimulate discussion, explore ideas by brainstorming, develop thinking skills for deep understanding, articulate their understanding by exchanging ideas and viewpoints, extended meaning and new applications for learning, and encourage students to search for more details (Ontario Curriculum Unit Planner, 2002, p. 113). Another activity could be presented is a problem in classroom activity to solve; in this activity, the instructor posts a problem and asks TEFL student-teachers to shape the desired situation of the final result of following planning organized procedures for problem solving and asks them to focus on the key steps of problem solving which include: defining the problem, identifying and defining the root causes, generating alternative solutions, evaluating the alternative, agreeing on the best solution, developing an action plan, and implementing and evaluating the solution (Rebori, n. d.).

Procedures for implementing Questions for flip classes or review questions or problem to solve:

- Preparing different types of question to encourages student-teachers' thinking, generate ideas, ask questions and consider practical questions and reflections, considering constructivism by asking questions that help to connect new knowledge and ideas with prior ones, encouraging students to respect each other's opinions and answers (Marai and Al-Hela, 2007, p. 35-40). The EFL student-teachers need to prepare a topic of next lecture and try to find out the answers of questions. Besides, EFL student-teachers can work in pairs/groups to complete the questions correctly. EFL student-teachers have to answer these questions by searching throughout the course's main reference or other references (Abou Shaaban, 2014, p. 586-587). In addition, reviewing questions could be presented to be answered by TEFL student-teachers themselves and asking only about questions they faced difficulties to answer or had different answers.

- Discussing the questions with student-teachers next lecture and ask them to check their answers and complete the missing gaps. 


\subsubsection{Open Discussion Topics or Reflection on the Lecture}

WhatsApp group open discussion means that all the group members 'whatever the number is' will participate in the discussion. Their contributions in the discussion will be vary among related, relevant or irrelevant. In this case, the instructor's role is very hard but s/he should figure out some criteria to manage open discussion or reflection on the lecture. The researcher suggested that the time of open discussion should be limited, all group members should respect others' comments and write short scientific comments and include evidence. Recent comments are read by the instructor to present the summery and last comment which highlights the valuable and relevant comments. In Mbukusa's (2018, p. 113) study, he allowed student-teachers to "record lectures and replay them in their own time for reflective purposes and then post any queries to colleagues."

Procedures for implementing open discussion topics or reflection on the lecture:

In order for reflection on the lecture to go well the following procedures should be followed:

- Posting an idea or argumentative issue on specific TEFL topic related to the previous or next lecture.

- Determining the time for posting comments.

- Asking the WhatsApp group members to read the comments well in order not to duplicate, to use clear language and to respect each other's comments.

- Reading comments, listing and categorizing them.

- Summarizing the common comments and presenting the summary for the WhatsApp group as a reminder and as an indicator for the end of the discussion.

\subsection{Characteristics of WhatsApp Activities}

Reviewing the related literature to using WhatsApp in teaching and learning, forming a focus group with (9) TEFL instructors from different universities and eliciting TEFL student-teachers' opinions about WhatsApp activities, the researcher came up with the following bases of using WhatsApp activities in TEFL courses successfully:

- Posting clear content and having clear instructions for doing the activities.

- Meeting TEFL student-teachers' language level or a level a bit higher than theirs.

- They should be short and not time consuming.

- To be logical not to distract them or overload them.

- The activity should be in its suitable time with the schedule of the course outline and topics.

- The instructor should follow it up.

- It must be balanced in order not to burden TEFL student-teachers.

- Instructor should specify the objective of each activity for the WhatsApp group member.

- $\quad$ Pay attention to download and upload size of the posted material.

3.3 TEFL Student-Teachers' Reflection on the Use of WhatsApp Activities in TEFL

TEFL student-teachers were asked to reflect on the use of the suggested WhatsApp activities in TEFL courses. They were asked to mention the benefits, the disadvantages and recommendations for improving their use. TEFL student-teachers' reflection was analyzed qualitatively to prepare a list of common statements. The final list was given again for TEFL student-teachers to find out the percentages of each statements according to their responses. Table (1) below shows TEFL student-teachers' quantitative reflection.

Table 1. TEFL Student-Teachers' Quantitative Reflection on WhatsApp Usage and Suggested Activities

\begin{tabular}{llc}
\hline No & \multicolumn{1}{c}{ Statements } & $\%$ \\
\hline$A^{-}$ & \multicolumn{1}{c}{ Benefits: WhatsApp helps me to: } \\
\hline$a^{-}$ & Pedagogical knowledge & $91 \%$ \\
\hline 1. & Build positive trends towards reading TEFL materials. & $91 \%$ \\
2. & Keep up-to-date by finding useful posted TEFL websites and reading materials. & $84 \%$ \\
3. & Enhance critical reading skills for reading TEFL materials. & $88 \%$ \\
4. & Build my own educational glossary. & \\
\hline
\end{tabular}




\begin{tabular}{|c|c|c|}
\hline$b-$ & Classroom Practices & \\
\hline 5. & Enhance the importance of using WhatsApp in the future job. & $93 \%$ \\
\hline 6. & See all the lesson stages in details through the posted videos. & $97 \%$ \\
\hline 7. & Create full image for future job reality. & $89 \%$ \\
\hline 8. & Encourage thinking of my role as a future teacher. & $89 \%$ \\
\hline 9. & Develop critical watching videos skills. & $93 \%$ \\
\hline 10. & $\begin{array}{l}\text { Grasp my attention to the classroom teacher's performance and reaction during the } \\
\text { whole lesson time. }\end{array}$ & $88 \%$ \\
\hline$c-$ & Review and Evaluation (quizzes or tests) & \\
\hline 11. & Get instant answers for misunderstood or difficult questions. & $98 \%$ \\
\hline 12. & Share feelings while studying for tests and quizzes. & $83 \%$ \\
\hline 13. & Support each other to study. & $83 \%$ \\
\hline 14. & Know the dates of quizzes. & $82 \%$ \\
\hline 15. & See tests and quizzes results and compare my own with others' results. & $99 \%$ \\
\hline$d-$ & Course requirements & \\
\hline 16. & Identify the course requirements through the instructor posts. & $96 \%$ \\
\hline 17. & Discuss each requirement in details with the instructor and group members. & $89 \%$ \\
\hline 18. & Know the dateline of each requirement. & $96 \%$ \\
\hline 19. & Get general written feedback for all assignments from the instructor. & $98 \%$ \\
\hline 20. & Watch videos more than once. & $97 \%$ \\
\hline$B-$ & Disadvantages: WhatsApp hinders my learning because it: & \\
\hline$a-$ & Technical and Security Problems & \\
\hline 21. & Demands internet connection. & $99 \%$ \\
\hline 22. & Needs smart phones for downloading the applications. & $90 \%$ \\
\hline 23. & Allows unfamiliar members to join in the group via the link. & $87 \%$ \\
\hline 24. & Allows sharing personal phone number with all. & $88 \%$ \\
\hline 25. & Cannot restrict receiving private messages from the group members. & $80 \%$ \\
\hline 26. & Makes me addicted to using WhatsApp. & $84 \%$ \\
\hline b- & Communication Problems: Group members: & \\
\hline 27. & Post wrong answers for some questions. & $80 \%$ \\
\hline 28. & $\begin{array}{l}\text { Repeat same questions more than once instead of revising posts and finding the } \\
\text { needed information. }\end{array}$ & $84 \%$ \\
\hline 29. & Post many intervention obstacles to follow instructor responses and posts. & $82 \%$ \\
\hline 30. & May be sometimes unfavored to communicate with. & $80 \%$ \\
\hline 31. & Misunderstand some interventions, which arouses conflict among group members. & $80 \%$ \\
\hline 32. & Consume time for following up posts. & $89 \%$ \\
\hline 33. & Are sometimes not dynamically participating. & $81 \%$ \\
\hline 34. & Post non-affiliated posts such as religious or general information. & $88 \%$ \\
\hline 35. & Talk about other courses. & $87 \%$ \\
\hline$C-$ & Recommendations for successful WhatsApp activities: & \\
\hline 36. & Specifying clear conditions, rules and instructions for interventions and posts to & $93 \%$ \\
\hline
\end{tabular}


37. Using WhatsApp in emergency situations in the Gaza Strip such as heavy rain and

$80 \%$ political instability in order to follow the course schedule as already planned in the beginning of the semester.

38. Sending students' grades in the course requirements via WhatsApp to let all $81 \%$ members know their level in the course as a kind of learning motivation for achievement.

39. Committing to a specific time for intervention and posts.

$97 \%$

$99 \%$ lecture.

41. Conducting simultaneous and asynchronous interactive discussions on some of the course topic.

42. Specifying a number of students to respond to students' inquiries regarding to administrative issues such as: quizzes and course assignments dates.

43. Keeping posting TEFL websites and reading materials followed by specific tasks.

Table (1) indicates that the percentage of agreement on benefits was in between ( $82 \%$ and $99 \%)$ similarly it was between (80\% and 99\%) regarding the disadvantages and recommendation statements. The highest percentage among benefits of WhatsApp use and the suggested activities was (99\%) for statement (15) followed by statements (11 \& 19) which scored (98\%) each. Meanwhile, the lowest percentage was for statement (14) which scored (82\%). This result matches with the ones presented by Robles, Guerrero, Llinás \& Montero (2019), Annamalai (2019) and Badawi (2009) who mentioned that students like using WhatApp as a helpful application in achieving the learning objectives and self-learning issues. Regarding disadvantages statements, it is clear that statement (21) scored the highest percentage, i.e. (99\%) while statements (30 \& 31) scored the lowest percentages, i.e. $(80 \%)$. As for the final part of the quantitative reflection which constituted recommendations, it was obvious that statement (40) scored the highest, i.e. (99\%) and statement (37) scored the lowest one, i.e. $(80 \%)$.

In brief, all statements in the quantitative reflection scored high percentage. That means all of these items are important to consider while adapting WhatsApp as a mediator in TEFL course and the instructor has to use creative suitable activities that meet the teaching/learning objectives of TEFL courses and facilitate WhatsApp application. Besides, the suggested activities varied between theoretical and practical TEFL materials, which help in enhancing the two parts: pedagogical knowledge and classroom practices. Moreover, these high percentages indicate that TEFL student-teachers have strong awareness to evaluate the role of using WhatsApp and the suggested activities by mentioning a great number of valuable benefits and disadvantages and presenting a set of recommendations for improving the use. The high percentages for all of the statements include another indicator that all TEFL student-teachers were participating in the WhatsApp group and found that group as a suitable environment to learn.

\section{Conclusion}

This study confirmed that there are different activities that can be inserted in TEFL courses to enhance pedagogical knowledge and classroom practices. TEFL student-teachers showed a great list of benefits of using WhatsApp and the suggested activities in achieving the objective of the TEFL courses and how this application meets their new desire in learning according to the current era requirements and characteristics. A number of disadvantages of using WhatsApp were presented to be considered by the instructor. Recommendations for improving the use of WhatsApp as a learning/teaching environment were presented. As a result, the use of WhatsApp and the suggested activities in TEFL course was recommended and the instructor has to be careful about the balance between this use and TEFL student-teacher's own timeline.

\section{Further Studies}

It would be interested to carry out the following suggested studies by researchers:

- The role of instructors in WhatsApp activities/chats.

- The use of WhatsApp activities in enhancing language skills.

- The use of WhatsApp among TEFL student-teachers or TEFL school teachers in facilitating learning.

- Exploring the effect of using one or more of the suggested WhatsApp activities on TEFL pedagogical knowledge and classroom practices by doing experimental studies. 


\section{References}

Abou Shaaban, S. (2014). EFL Student-Teachers' Evaluation and Attitude towards Using some Active Teaching Strategies on Developing Effective TEFL Course. Asian Journal of Humanities and Social Studies, 2(4). Retrieved from https://www.ajouronline.com/index.php/AJHSS/article/view/1479

Abou Shaaban, S., Abu Shawish, J., \& Jalambo, M. (2019). Integration of ICT in EFL/ES Teachers' Training and Self-Efficacy Beliefs as Perceived by the Trainers. Humanities \& Social Sciences, 7(4), 863-875. https://doi.org/10.18510/hssr.2019.74115

Abou Shaaban, S., \& Shaat, M. (2019). A Scenario-based Learning Approach for Enhancing AL-Azhar University-Gaza Student-Teachers' TEFL Practices in Inclusive Education Classes. Innovations and Best Practices of Teaching and Learning English in Palestinian HEIs Conference, Palestine Technical University-Kadoorei/Tulkarm \& AL-Quds Open University.

Adams, J. (2019). WhatsApp with Science? Emergent Cross Action Spaces for Communication and Collaboration Practices in an Urban Science Classroom. Emergent Practice and Material Conditions in Learning and Teaching with Technologies. Tersa C. Parman \& Isa Jahnke (Eds.), Springer: Gewerbestrasse, 107-126. https://doi.org/10.1007/978-3-030-10764-2_7

Alderman, S. (2017). 5 Ways to Use WhatsApp in the ELT Classroom. Retrieved from https://www.english.com/blog/5-ways-use-whatsapp-elt-classroom/

Alsowayegh, N., \& Garba, I. (2019). WhatsApp for Defamiliarizing Foundation Year English Learners: A Collaborative Action Research Evaluation. Proceedings of the 1st International Conference on Smart Innovation Ergonomics and Applied Human Factors (SEAHF), Peces, C. B., Slama, S. B., \& Zafer, B. (Eds.), Springer: Switzerland, 91-97. https://doi.org/10.1007/978-3-030-22964-1_10

Annamalai, N. (2018). How Do We Know What Is Happing In WhatsApp: A Case Study Investigating Pre-service Teachers' Online Activity. Malaysian Journal of Learning and Instruction, 15(2), 207-225. Retrieved from http://mjli.uum.edu.my/

Annamalai, N. (2019). Using WhatsApp to Extend Learning in A Blended Classroom Environment. Teaching English with Technology, 19(1), 3-20. Retrieved from http://www.tewtjournal.org

Badawi, M. (2009). Using Blended Learning for Enhancing EFL Prospective Teachers' Pedagogical Knowledge and Performance. Conference Paper: Learning \& Language - The Spirit of the Age, Ain Shams University Guest House, Cairo, Egypt, 14-15.

Bell, T. (1998). Extensive Reading: Why and How? The Internet TESL Journal, IV(12). Retrieved from http://iteslj.org/Articles/Bell-Reading.html

Bensalem, E. (2018). The Impact of WhatsApp on EFL Students' Vocabulary Learning. Arab World English Journal (AWEJ), 9(1). http://doi.org/10.2139/ssrn.3150707

Bloder, R., \& Waldman, R. (2019). The Role of WhatsApp Group of a Professional Learning Community of Chemistry Teachers in the Development of their Knowledge. Forkosh Baruch, Alona Meishar Tal, Hagit (Eds.), Mobile Technologies in Educational Organizations, IGI Global: British Library, 117-141. https://doi.org/10.4018/978-1-5225-8106-2.ch007

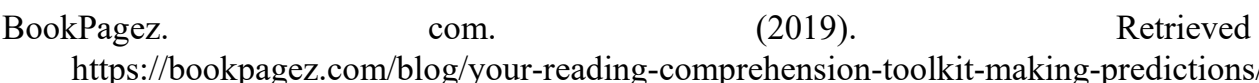

British Council. (n. d.). Prediction. Retrieved from https://www.teachingenglish.org.uk/article/prediction

Coffey, A. (2014). Using Video to Develop Skills in Reflection in Teacher Education Students. Australian Journal of Teacher Education, 39(9). http://doi.org/10.14221/ajte.2014v39n9.7

Cox, J. (n. d.). 5 Effective Teaching Strategies for Reading. Retrieved from https://www.teachhub.com/5-effective-teaching-strategies-reading

Hamad, M. (2017). Using WhatsApp to Enhance Students' Learning of English Language "Experience to Share". Higher Education Studies, 7(4). http://doi.org/10.5539/hes.v7n4p74

Lakshmi, D. (2018). A Hand Guide for Teachers and Researchers: ICT Embedded Education and Research: A Hand Guide for Teachers and Researchers. Nation Press: McNichols.

Mariappan, J., Shih, A., \& Schrader, P. (2004). Scenario-Based Learning in Teaching Statics. American Society. Engineering Education Annual Conference and Exposition, American Society for Engineering Education. 
Mbukusa, N. (2018). Perceptions of Students on the Use of WhatsApp in Teaching Methods of English as Second Language at University of Namibia. Journal of Curriculum and Teaching, 7(2), 112-119. https://doi.org/10.5430/jct.v7n2p112

McMains, L. (2017). Inclusive Education: What It Means, Proven Strategies, and a Case Study. Retrieved from https://education.cu-portland.edu/blog/classroom-resources/inclusive-education/

Meşe, C., \& Gökçe Aydın. (2019). The Use of Social Networks among University Students. Academic Journals, 14(6), 190-199. https://doi.org/10.5897/ERR2018.3654

Muff, K., \& Thomas et al. (2013). Management Education for the World: A Vision for Business Schools Serving People and Planet. Edward Elgar: Massachusetts.

Ontario Curriculum Unit Planner. (2002). Teaching/Learning Strategies Companion, Queen's Printer for Ontario. Retrieved from www.edu.gov.on.ca/eng/policyfunding/ocup/documents/telrsta2002.pdf

Rebori, R. (n. d.). Effective Problem Solving Techniques for Groups. Retrieved from https://www.unce.unr.edu/publications/files/cd/other/fs9726.pdf

Robles Heydy, Guerrero, J., Llinás, H., \& Montero, P. (2019). Online Teacher-Students Interactions Using WhatsApp in a Law Course. Journal of Information Technology Education: Research, 18, 231-252. https://doi.org/10.28945/4321

Rosaen, C., Lundeberg, M., Cooper, M., \& Fritzen, A. (2019). Noticing How Does Investigation of Video Records Change How Teachers Reflect on Their Experiences? Journal of Teacher Education. https://doi.org/10.1177/0022487108322128

Scenario-based Learning. (n. d.). What is it? Retrieved from https://blog.commlabindia.com/elearning-design/scenario-based-learning-what-and-why

Taneri Ahu. (2018). Scenario-Based Case Study Method and the Functionality of the Section Called 'from Production to Consumption' from the Perspective of Primary School Students. Asian Journal of Education and Training, 4(1), 56-61. https://doi.org/10.20448/journal.522.2018.41.56.61

\section{Copyrights}

Copyright for this article is retained by the author(s), with first publication rights granted to the journal.

This is an open-access article distributed under the terms and conditions of the Creative Commons Attribution license (http://creativecommons.org/licenses/by/4.0/). 